\title{
Criação e uso de modelo didático da molécula de DNA com materiais de baixo custo
}

\author{
Creation and use of didactic model of the DNA molecule with low-cost materials \\ Creación y uso de modelo didáctico de la molécula de ADN con materiales de bajo costo
}

Recebido: 20/06/2021 | Revisado: 26/06/2021 | Aceito: 01/07/2021 | Publicado: 14/07/2021

\author{
Marines Marli Gniech Karasawa \\ ORCID: https://orcid.org/0000-0001-8431-0150 \\ Universidade Estadual Paulista "Júlio Mesquita Filho", Brasil \\ E-mail:mgniechk@yahoo.com.br
}

\begin{abstract}
Resumo
$\mathrm{O}$ uso de materiais didáticos em disciplinas de genética tem se tornado uma prática com demanda crescente em função da elevada eficiência que tem proporcionado no ensino e no aprendizado de temas microscópicos impossíveis de serem visualizados a olho nu. Esta técnica proporcionou aulas práticas mais dinâmicas e descontraídas, com maior compreensão, o aprendizado, foco, o interesse e a colaboração entre os alunos durante os trabalhos em grupo, reduziu a dispersão e o uso de celulares em sala de aula. Além disto, segundo o bibliotecário da Unesp houve um aumento considerável na busca e uso de livros na biblioteca pelos alunos quando comparado aos últimos anos. Em contrapartida, um fator que tem aumentado o interesse na adoção de materiais didáticos por parte dos docentes é o baixo custo envolvido na sua produção quando comparado ao custo elevado dos reagentes e equipamentos utilizados nas aulas práticas tradicionais realizadas em laboratórios. O nosso objetivo é apresentar detalhes da contrução da molécula de DNA utilizando materiais didáticos de baixo custo, as estapas envolvidas na criação e as formas de avaliação utilizadas pela autora para chegar nos resultados apresentados e, discutir o seu uso no ensino superior. Este modelo didático foi desenvolvido no início da carreira acadêmica da autora e testado no ensino das disciplinas de genética, biologia geral e biologia molecular de diferentes cursos ao longo de vários anos.
\end{abstract}

Palavras-chave: Material didático; Baixo custo; Ensino; Genética; Biologia molecular.

\begin{abstract}
The use of teaching materials in genetics disciplines has become a practice with increasing demand due to the high efficiency it has provided in teaching and learning of microscopic subjects impossible to be seen with the naked eye. This technique produced dynamic and relaxed practical lessons, with greater understanding, learning and concentration, and the interest and collaboration among students during group work, and reduced the dispersion and use of cell phones in the classroom. In addition, according to the Unesp librarian, there was an increase in the search and use of books from the library by students when compared to last years. On the other hand, a factor that has increased the interest in the adoption of didactic materials by teachers is the low cost of production compared to the high cost of reagents and equipment used in traditional practical classes used in laboratories. Our aim is to present details of the construction of the DNA molecule using inexpensive didactic materials, the steps evolved in the creation and the forms of evaluation used by the author to achieve the presented results, and discuss its use in the higher education. This didactic model was developed at the beginning of the author's academic career and used in the teaching of genetics, general biology and molecular biology disciplines in different courses over several years.
\end{abstract}

Keywords: Didactic material; Low cost; Teaching; Genetics; Molecular biology.

\section{Resumen}

El uso de materiales didácticos en disciplinas de la genética se ha convertido en una práctica con una demanda creciente debido a la alta eficiencia que ha proporcionado en la enseñanza y el aprendizaje de materias microscópicas imposibles de ver a simple vista. Esta técnica ha proporcionado lecciones prácticas dinámicas y relajadas, con myor comprensión, aprendizaje, concentración, el interés y la colaboración entre los estudiantes durante el trabajo en grupo, reducido la dispersión y el uso de teléfonos celulares en el aula. Además, según el bibliotecario de la Unesp, hubo un aumento considerable en la búsqueda y uso de libros en la biblioteca por parte de los estudiantes en comparación con los últimos años. Por otro lado, un factor que ha incrementado el interés en la adopción de materiales didácticos por parte de los docentes es el bajo costo que implica su producción en comparación con el alto costo de los reactivos y equipos utilizados en las clases prácticas tradicionales impartidas en los laboratorios. Nuestro objetivo es presentar detalles de la construcción de la molécula de ADN utilizando materiales didácticos económicos, los pasos involucrados en la creación y las formas de evaluación utilizadas por el autor para llegar a los resultados presentados y discutir su uso en la educación superior. Este modelo didáctico fue desarrollado al inicio de la carrera académica del autor y utilizado en la enseñanza de la genética, biología general y biología molecular de diferentes cursos durante varios años.

Palabras clave: Materiales didácticos; Bajo costo; Enseñando; Genética; Biología molecular. 


\section{Introdução}

O interesse pelos mecanismos de controle e transmissão de características hereditárias atraiu a atenção dos seres humanos desde os primórdios da humanidade. Entretanto, foi apenas no século XIX, que os estudos realizados por Gregor Mendel envolvendo a produção de linhas puras seguida de uma série de hibridação utilizando a ervilha Pisum sativum como material experimental foram capazes de desvendar as leis que governam a herança, tendo definido a "Lei da segregação" e a "Lei da distribuição independente" (Griffiths et al., 2016; Pierce, 2016; Ramalho et al., 2012).

Dentre os motivos que levaram Mendel ao sucesso foram o uso de material de fácil cultivo, crescimento rápido, prole abundante, análise isolada de cada característica estudada, uso de linhas puras, documentação detalhada dos cruzamentos e seus resultados do experimento, formulação de hipóteses e a análise estatística dos resultados obtido (Ramalho et al., 2012; Griffiths et al., 2016; Pierce, 2016). Contudo, os resultados divulgados por Mendel em 1865 não foram compreendidos pela sociedade científica da época porque ele associou dados biológicos e estudos estatísticos de probabilidade. Somente 30 anos após, no início do século XX, que estudos de hibridação realizados por De Vries e outros cientistas foram capazes de obter resultados semelhantes aos de Mendel o que levou ao redescobrimento das Leis de Mendel e deu origem a uma nova área de estudo hoje conhecida como Genética (Martins \& Prestes, 2016).

Com a criação da Genética, vários avanços importantes foram verificados na busca da compreensão das partículas hereditárias descritas por Mendel. O surgimento da microscopia permitiu a observação do núcleo presente no interior das células, onde foi constatado que o comportamento dos cromossomos seguia a segregação proposta por Mendel durante a formação dos gametas na meiose e deu origem a "Teoria cromossômica da herança" (Santos et al., 2015). Contudo, era necessário comprovar qual dos componentes presentes no núcleo (DNA, RNA ou proteínas) era responsável pela transferência das características hereditárias de uma geração para a outra. Experimentos realizados pelos cientistas Griffth e Avery, com bactérias e, Hershey e Chase, com vírus, mostraram de forma definitiva que o material genético presente nas partículas hereditárias era o DNA (Griffiths et al., 2016; Pierce, 2017).

Uma vez consolidado que o DNA armazenava as informações hereditárias, buscou-se compreender a sua estrutura e organização dos componentes químicos na molécula. Neste sentido, os estudos de difração de Raio X realizados por Rosalind Franklin indicavam tratar-se de uma molécula helicoidal e os experimentos de Erwin Chargaff revelaram que a molécula era composta por purinas e pirimidinas, e que as bases nitrogenadas apresentavam pareamento da adenina com timina $(\mathrm{A}=\mathrm{T}) \mathrm{e}$ citosina com guanina $(\mathrm{C}=\mathrm{G})$. O uso destas informações associadas as leis da química estrutural permitiram que James Watson \& Francis Crick construíssem o primeiro modelo tridimensional da molécula de DNA e, em 1953, publicassem na Nature a proposta do modelo de dupla hélice de DNA mostrando pareamento complementar entre as bases nitrogenadas no interior da molécula e orientação antiparalela das cadeias (Ramalho et al., 2012; Nelson \& Cox, 2014; Zaha, 2014). Na publicação feita por Watson e Crick foi proposto, ainda, com base na estrutura do DNA que o material genético era armazenado na molécula, mas de alguma forma a informação ali contida deveria ser transferida para uma molécula intermediária para que pudesse ser traduzida na forma de proteínas para desempenhar as inúmeras funções dos organismos vivos. Esta constatação ficou conhecida como "Dogma central da biologia" (Snustad \& Simmons, 2013; Griffiths et al., 2016; Pierce, 2017).

Várias pesquisas posteriores tiveram como principal preocupação desvendar como o material genético era replicado, transcrito e traduzido em uma proteína funcional. A descoberta descoberta das enzimas de restrição e o desenvolvimento de novas tecnologias permitiu o rápido avanço no conhecimento do material genético permitindo que atualmente sejamos capazes de identificar, interferir e manipular genes de modo a desvendar o parentesco, desvendar situações criminais, controlar doenças, produzir plantas resistentes a fatores bióticos e abióticos, alterar a qualidade nutricional de muitos alimentos, entre outros. Estes avanços fizeram com que a Genética se tornasse uma Ciência de grande importância em várias áreas do conhecimento científico e no cotidiano de toda a humanidade. 
Com todos estes avanços, o ensino de temas de Genética tem se tornado uma tarefa desafiadora exigindo constante atualização por parte dos docentes e laboratórios cada vez mais sofisticados para viabilizar o ensino de seu conteúdo. Apesar disto, mesmo sob condições ótimas de ensino, é bastante comum alunos do Ensino Médio e Superior apresentarem dificuldades na compreensão dos conceitos e mecanismos envolvidos na transferência da informação genética devido a dificuldade de visualização em práticas laboratoriais. Em contrapartida, o elevado custo das aulas práticas de laboratório e a redução constante da verba recebida do setor governamental tem tornado cada vez mais difícil o uso deste tipo de abordagem em aulas práticas pelo elevado custo envolvido na aquisição de reagentes, vidrarias e equipamentos. E, com o sugimento da pandemia da Covid-19 o setor do ensino vivencia um novo desafio que é transferir os conhecimentos, antes realizados de forma presencial, de forma remota. Além disto, a instabilidade econômica e a grave crise financeira vivenciada no país tem agravado os problemas existentes e a precariedade anteriormente vivenciada, com reais ameaças de fechamento muitas Instituições de Ensino Superior e setores inteiros de universidades importantes como a UFRJ, UFSCar, entre outras, o que vem afetando de forma direta a área da genética dificultando cada vez mais a produção de ensino de qualidade. Atualmente a grande maioria das instituições de ensino não possui condições de executar práticas de laboratório sofisticadas. Deste modo, comumente lançam mão do uso das abordagens tradicionais no ensino, tais como aulas expositivas, uso de textos e exercícios presentes em livros.

Considerando as dificuldades supra-citadas, tem sido crescente a importância e o uso de materiais didáticos que facilitem o aprendizado dos conceitos e tornem o ensino mais dinâmico auxiliando na compreensão dos tópicos ensinados. De acordo com Souza et al., 2020 os modelos didáticos são ferramentas que facilitam a aprendizagem e Santana \& Silva (2010), afirmam que o uso de modelos didáticos permite sedimentar o conteúdo em sala de aula e instiga a curiosidade dos alunos aumentando qualidade dos mecanismos de ensino-aprendizagem. E, segundo Gerpe, (2020) os materiais didáticos estimulam o trabalho em grupo permitindo a construção de conhecimento coletiva, sendo metodologias eficientes no ensino de citologia (Carvalho \& Oliveira, 2021) e contribuindo nas atividades inclusivas para deficientes visuais (Michelotti \& Loreto, 2019). Além disto, visual colorido dos modelos didáticos estimula o aluno a manipular e manter a atenção nos detalhes, promovendo a reflexão crítica o conteúdo ensinado, o que melhora a compreensão do tema. Entretanto, apesar dos inúmeros benefícios, a adoção desta prática ainda é reduzida no ensino acadêmico.

Diante dos relatos do efeito positivo do uso dos modelos didáticos no ensino, buscamos avaliar a construção do modelo didático da molécula de DNA em aulas práticas. Neste sentido, visando mudar este cenário e promover um ensino de maior qualidade a custos menores iniciamos, em 2007, o processo de criação e uso de materiais didáticos de baixo custo.

O nosso objetivo é apresentar detalhes da contrução da molécula de DNA utilizando materiais didáticos de baixo custo, as estapas envolvidas na criação e as formas de avaliação utilizadas pela autora para chegar nos resultados apresentados e discutir o seu uso no ensino superior.

\section{Metodologia}

No estudo foram utilizadas várias turmas de alunos pertencentes a diferentes cursos e disciplinas de três universidades públicas alocadas em diferentes Estados federativos do Brasil, a saber: uma na Bahia, uma em Minas Gerais e uma em São Paulo. No ano de 2007 iniciamos, na Universidade Estadual do Sudoeste da Bahia (UESB), o processo de criação do modelo didático para o ensino da estrutura da molecular de DNA utilizando artefatos de isopor e madeira. Após definir o material adequado para construção do modelo (Fase 1) avaliamos a forma de aplicação, individual e em grupos de diferentes tamanhos (Fase 2), em diferentes cursos e turmas da Universidade Federal de Alfenas (UNIFAL), no período de 2009-2010 e, no ano de 2011 a não aplicação do modelo didático elaborado no ensino da estrutura de DNA. E, em 2019, avaliamos duas turmas de genética do curso de Agronomia da Universidade Estadual Paulista "Júlio Mesquita Filho" (UNESP). 
O método aplicado nas turmas foi a pesquisa populacional (Estrela, 2018) com estudo de caso (Gomes, 2008; Pereira, 2018) no modelo de estudo de casos múltiplos (Silva \& Mercês, 2017; Estrela, 2018;) e análises qualitativas dos resultados (Lüdke, 2018).

\subsection{Preparo do material para a aula prática}

Para problematizar o tema da aula teórica sugerimos que o professor busque acessar o material DNA: diálogo, genética e argumentação (Silva e Silva, 2018). Ao final da aula teórica sobre estrutura da molécula do DNA o professor deve solicitar que os alunos comprem 2 placas de isopor de 1,5 cm, 1 caixa de palitos de dentes, tinta guache ou acrílica (cores: azul, vermelha, amarela, verde e laranja), 1 pincel de ponta chata, 1 estilete de metal e cola de isopor. Em casa, os alunos devem para recortar no isopor as estruturas das bases nitrogenadas, açúcares e fosfatos do isopor no tamanho indicado abaixo utilizando o estilete, que pode ser aquecido na chama para melhorar o aspecto final, e pintar, respectivamente: 5 adeninas (A) na cor azul, 6 citosinas (C) na cor amarela, 6 guaninas (G) na cor vermelha, 4 timinas (T) na cor verde, 20 desoxirriboses (D) na cor branca e o 20 fosfatos (P) na cor laranja (Figura 1).

Figura. Estrutura das bases nitrogenadas, açúcar e fosfato utilizadas na construção da molécula de DNA.

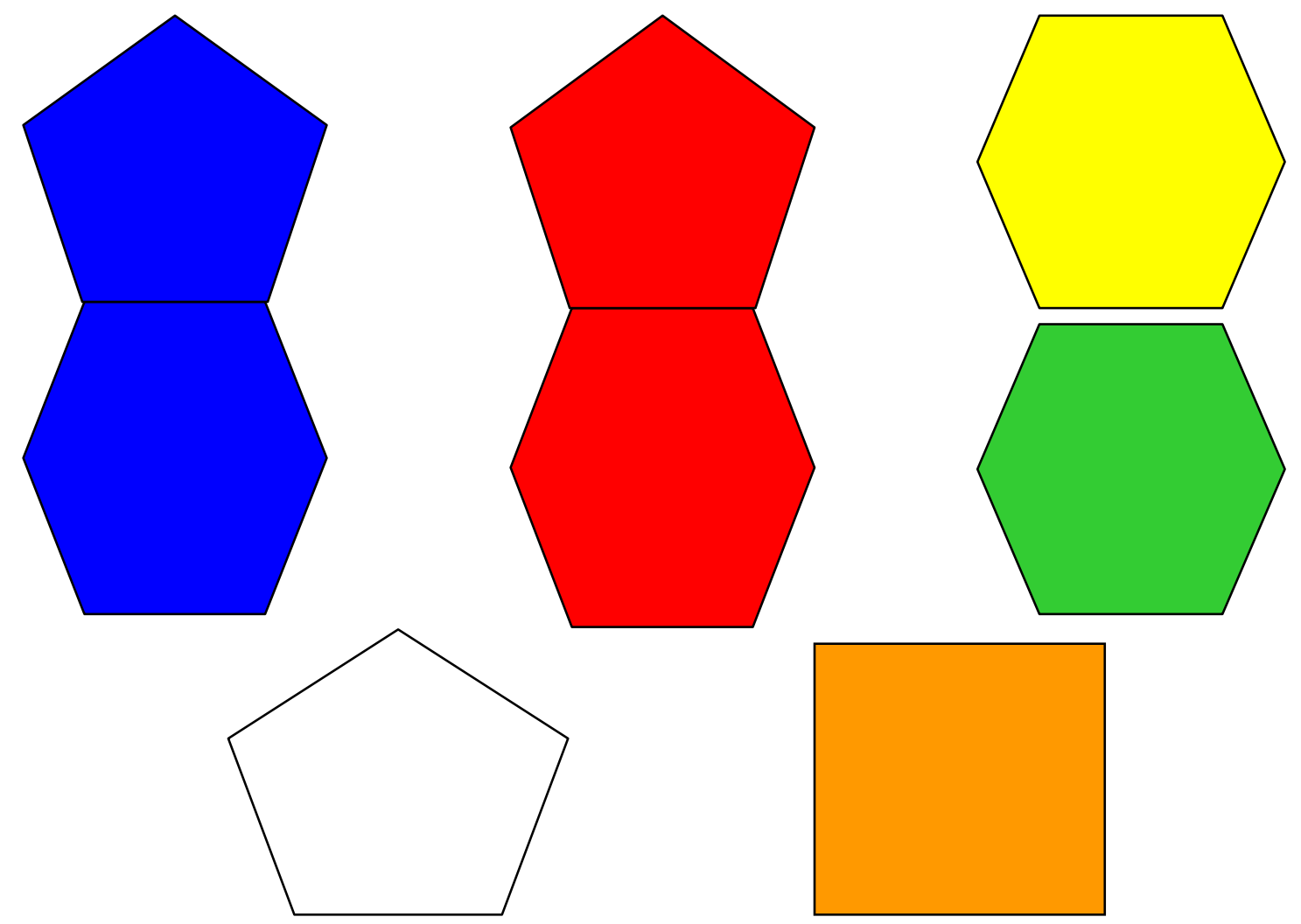

Fonte: Esquema elaborado pela autora.

\subsection{Material necessário para a execução da aula prática}

Para produzir uma molécula de DNA ilustrada na Figura 2, solicitar aos alunos que tragam as peças pintadas, a placa de isopor, os palitos de dente e a cola de isopor. Na aula prática deve-se utilizar a sequência indicada abaixo no processo de montagem. A prática pode ser realizada individualmente ou em grupo. 
Figura 2. Estrutura da molécula de DNA.

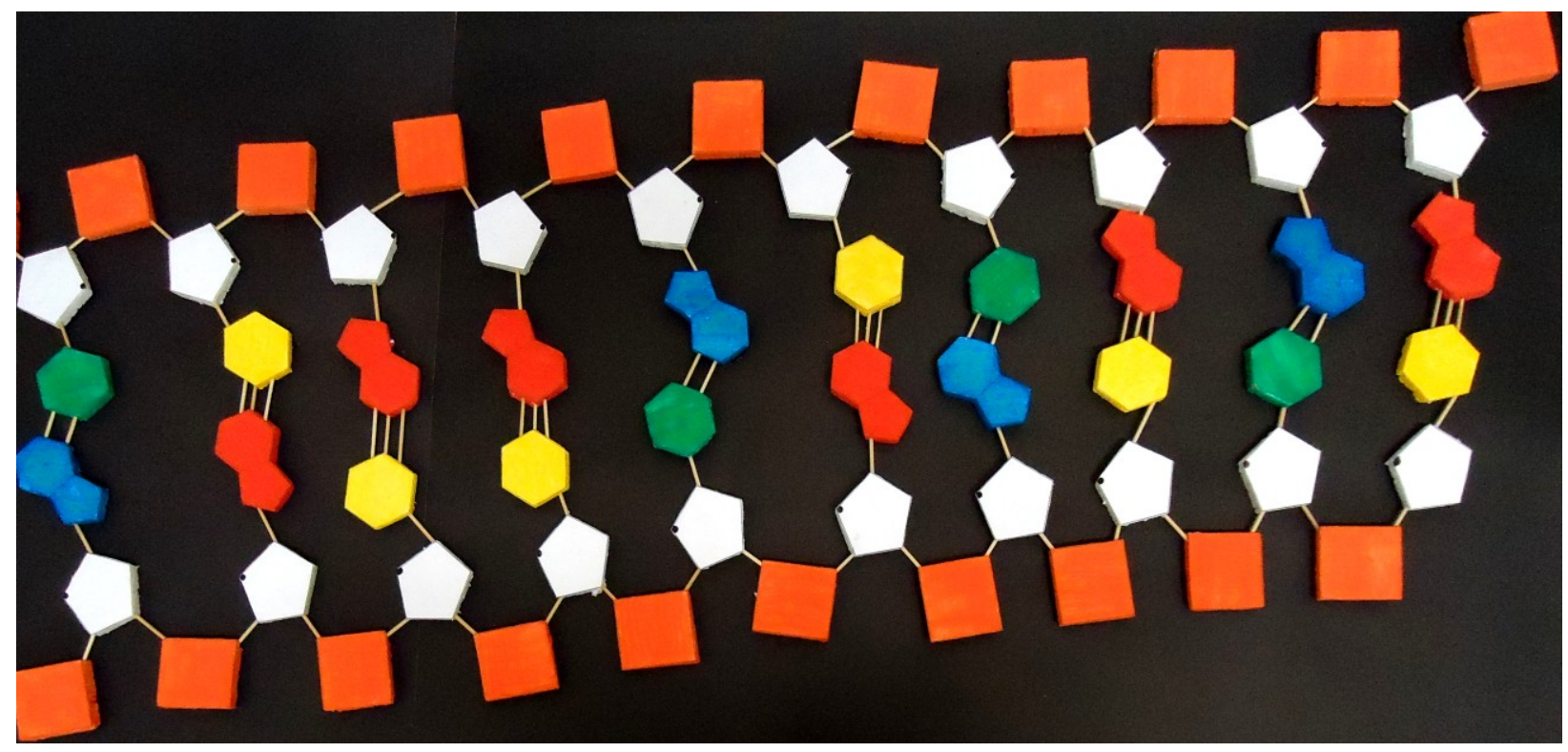

Nesta imagem o professor deverá observar: a localização dos carbonos utilizados na ligação química e a angulação correta das ligações entre as bases nitrogenadas, açúcares e fosfatos. Além disto, deve ser observada a orientação correta da desoxirribose (ver posição do anel aromático) que está indicado por um ponto e também fazer atenção sobre a condição antiparalela das fitas, sendo que os fosfatos devem ficar livres na extremidade 5 'da molécula.

Fonte: Material da autora

Recomendamos que a aula prática seja conduzida na biblioteca ou em uma sala onde existam mesas ou bancadas para que os alunos possam manipular de forma confortável todo o material. Além disto, em nossa aula prática induzimos o aluno a consultar livros de genética e de bioquímica para certificar: o tipo de ligação química existente entre as bases nitrogenadas, orientação do anel aromático da desoxirribose (fazer um ponto um ponto para indicar o anel aromático), o posicionamento dos fosfatos na extremidade 5'e 3' e o ângulo da ligação das bases nitrogenadas (A, T, C e G) para evitar conflito estérico. Além disto, que observassem os união antiparalela das fitas e todos os demais detalhes abordados em aula teórica sobre as características da estrutura da molécula de DNA.

Durante o processo de montagem o professor atuará como tutor explicando detalhes da estrutura do DNA e tirando dúvidas sobre as características da molécula ensinados na aula teórica. Para complementar o assunto sobre a estrutura tridimensional de dupla-hélice recomendo que seja utilizada a dobradura feita em papel do trabalho publicado por Yen (1995) na revista Trends in Biochemical Sciences, sob o título "Make your own DNA". Trata-se de um holograma que pode ser impresso em papel sulfite que, através da técnica de dobradura, permite obter uma molécula de DNA de estrutura tridimensional (Figura 3). O professor poderá imprimir o holograma numa folha de sulfite e realizar, juntamente com os alunos, a dobradura enquanto explica aspectos fundamentais da estrutura do B-DNA. 
Figura 3. Molécula de DNA produzida a partir da dobradura de papel.

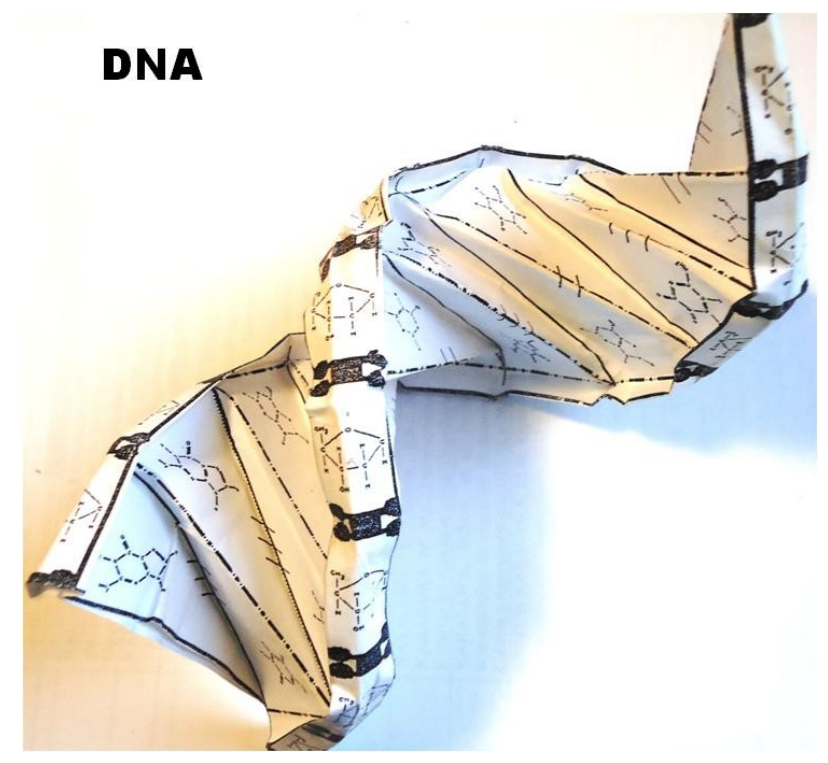

Esta dobradura poderá ser utilizada para demonstrar o sulco maior e o sulco menor, o antiparalelismo das fitas e discutir a distância entre os pares de bases no interior da molécula do B-DNA, a qual representa

Fonte: Material da autora.

\subsection{Fase 1- Criação e avaliação do modelo - realizadao na UESB}

Os estudos da UESB foram realizados, no ano de 2007, com duas turmas do curso de Agronomia contendo 40 alunos cada. Nas aulas práticas uma turma realizou a construção do modelo (figura 2) utilizando isopor e palito de dente ou metal e a outra turma utilizou madeira e pedaços de arame liso na construção do mesmo modelo. Utilizamos a madeira, pois existia o intuito de produzir um material permanente conforme era utilizada nas aulas práticas de turmas na ESALQ/USP. Nesta etapa verificamos: impacto do material utilizado na construção do modelo no processo de aprendizagem dos alunos afim de definir o melhor material. Foram verificados: compreensão, conhecimento teórico, nível de acertos na montagem do modelo.

\subsection{Fase 2 - Validação do modelo criado - realizado na UNIFAL e na UNESP}

O modelo da molécula de DNA criado em isopor, selecionado em 2007 na UESB, foi testado em aulas práticas na Universidade Federal de Alfenas (UNIFAL), no ano de 2009, com 53 alunos da turma do curso de Biologia, no ano de 2010 com 40 alunos da turma de Biotecnologia e, no ano de 2011, nenhuma turma recebeu práticas de montagem do modelo. Na Unifal verificamos o processo de aprendizagem sobre a estrutura da molécula de DNA quando houveram aulas práticas de montagem do modelo realizada de forma individual e em grupos de 3 a 4 alunos comparado com as turmas que não receberam as práticas de montagem do modelo.

Na Universidade Estadual Paulista "Júlio Mesquita Filho" (UNESP) testamos o modelo criado em aulas práticas com 22 alunos da turma A e 18 alunos da turma B, pertencentes ao curso de Agronomia. Na Unesp avaliamos a montagem da molécula em grupos de 2 e 3 alunos.

$\mathrm{Na}$ fase 2 do estudo foram verificados: compreensão e aprendizado em questões de prova, nível de acertos na montagem do modelo (aspectos relacionados a estrutura do modelo preparado pelo estudante ou grupo de estudantes, tais como: ligações químicas corretas entre as peças, angulação correta, orientação do anel aromático da desoxirribose, posicionamento dos fosfatos na extremidade 5'e 3'da molécula, etc) comparando-se a montagem individual e em grupos com as turmas controle que não receberam a prática de montagem do modelo. Além disto, foi observado o nível de participação, colaboração e interação, grau de isolamento dos discentes e foco na atividade e grau de dispersão. 


\section{Resultados e Discussão}

A partir da união dos açúcares, fosfatos e bases nitrogenadas previamente recortadas e pintadas na sequência indicada no item material e métodos deverá ser gerada uma molécula conforme indicado na Figura 2. Este modelo foi idealizado pela autora em 2007 e testado em pesquisa populacional (Estrela, 2018) associado a estudos de caso (Gomes, 2018; Pereira et al., 2018) numa abordagem de casos múltiplos (Silva \& Mercês, 2017). Segundo Estrela (2018) a pesquisa populacional permite obter associações fortes em função de observações repetidas e fornece subsídios para a tomada de decisão, a nível de indivíduo e de população, enquanto, os casos múltiplos permitem explorar de forma intensa e aprofundar o conhecimento sobre situações específicas associadas ao material de estudo, no caso o uso de modelos didáticos para o estudo da estrutura de DNA. E, de acordo com Lüdke (2018) estudos de caso permitem retratar a realidade de forma completa e consistente.

$\mathrm{Na}$ Fase 1, realizada na UESB, foram utilizadas duas turmas de 40 alunos cada e testados dois diferentes materiais na construção do modelo, a madeira e o isopor, com o intuito avaliar e validar os modelo mais adequado estabelecendo causas e efeitos, testando a validade e a confiança (Gomes, 2008; Pereira, 2018) do modelo criado. No estudo, uma turma montou, em aula prática, a molécula de DNA utilizando as peças que representavam os componentes químicos, construídos em madeira enquanto a outra turma montou a molécula utilizando as peças construídas com isopor (Figura 4).

Figura 4. Molécula de DNA produzida pelos alunos da UESB utilizando de peças de isopor.

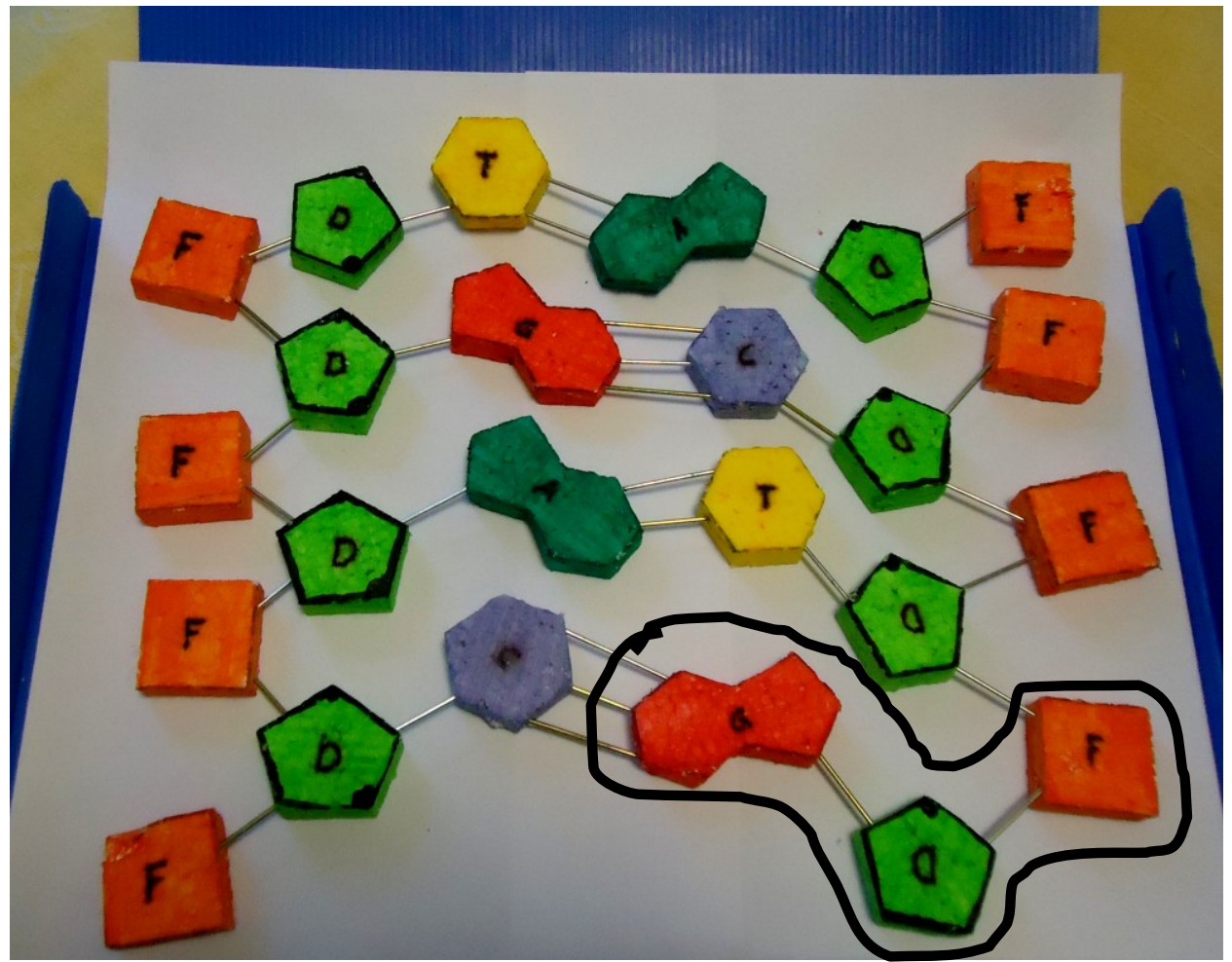

Este modelo foi construído individualmente num tamanho menor que o proposto. O destaque, em preto, mostra um nucleotídeo que o professor pode utilizar para explicar os componentes que fazem parte da estrutura do DNA. Em seguida, pode explicar os tipos de ligação de cada componente químico, como as bases nitrogenadas se associam no interior (tipo de ligação) e qual a razão de serem alocadas na parte interna (polaridade).

Fonte: Foto do material da autora.

Os modelos da estrutura da molécula de DNA construídas em madeira apresentaram alguns inconvenientes, tais como: custo mais elevado e redução na eficiência da compreensão e do aprendizado porque a presença do furo na madeira induziu o aluno a realizar a ligação correta entre as peças, sem grande esforço, num menor tempo de montagem da molécula e também mostram menor compreensão do tema na avaliação. Em contrapartida, as moléculas construídas com peças de isopor, 
apesar de possuir durabilidade menor, mostraram inúmeros benefícios não encontrados na molécula de madeira. Entre eles, podemos citar: baixo custo na aquisição, não possuir nenhuma indicação prévia do local, tipo e número de ligações necessários entre os diferentes componentes químicos (bases nitrogenadas, açúcares e fosfatos). Além disto, permite que o aluno produza e mantenha consigo o seu próprio material o que viabiliza o esclarescimento de dúvidas sobre a estrutura e a composição química da molécula de DNA durante os estudos. Isto agiliza a memorização e também amplia a compreensão sobre questões relativas as propriedades químicas da molécula. Além disto, o aspecto colorido cativa e atrai a atenção sobre a imagem e o aspecto tridimensional permite o uso com deficientes visuais (Michelotti \& Loreto, 2019), com alunos com baixo índice de atenção, entre outros. Verificou-se que os alunos da turma que montaram o modelo de isopor apresentaram compreensão maior do tema sendo capaz de descrever a estrutura do DNA com detalhes e minúncias, fato não observado na turma que utilizou peças de madeira.

A prática do preparo de materiais didáticos foi iniciada em 2007 UESB com alunos do curso de agronomia na disciplina de biologia geral e, em vista dos resultados positivos observados no uso e manipulação de materiais didáticos tridimensionais coloridos demos continuidade a aplicação desta prática com o intuito de compreender melhor os efeitos do uso dos modelos didáticos e validar o material produzido para o estudo da estrutura de DNA. Para tanto, avaliamos de forma qualitativa os alunos das disciplinas de genética e biologia molecular ministradas na Universidade Federal de Alfenas (UNIFAL) após assumirmos em 2009. No ano de 2010, a prática foi utilizada apenas com alunos do curso de Biotecnologia enquanto as turmas de genética de 2011, não receberam aulas práticas com o modelo proposto.

$\mathrm{Na}$ Unifal, pudemos observar claramente que as turmas que não receberam a aula prática de montagem do modelo tiveram muito mais dificuldade para compreender o assunto e discorrer sobre o tema, mostraram um índice muito maior de dispersão e isolamento, além dos problemas de interação e colaboração enquanto as turmas que realizaram montagem individual do modelo mostraram um elevado índice de aprendizado e compreensão sobre o assunto sendo capazes de descrever minunciosamente a estrutura da molécula, também reduziu a dispersão, aumentou o foco e concentração, entretanto os problemas de isolamento e falta de colaboração permaneceram. Em contrapartida, quando se utilizou grupos de 3 a 4 alunos aumentou o nível de colaboração entre os alunos e participação em sala de aula, entretanto reduziu o nível de compreensão sobre o assunto e o nível de participação dos estudantes na montagem da molécula.

Vale ressaltar, ainda, que em função da crescente demanda dos alunos para continuar trabalhando com materiais didáticos decidimos criar o projeto de Extensão "Popularização da Genética" com objetivo elaborar outros materiais didáticos de baixo custo para auxiliar no ensino de temas relacionados de genética e biologia molecular, oferecer cursos (https://www.unifal-mg.edu.br/extensao/cursos-de-extensao-ministrados-em-2011/) para ensinar professores e alunos trabalharem com os materiais didáticos criados no projeto e retribuir para a sociedade todo o conhecimento que autora $\mathrm{e}$ coordenadora do projeto recebeu o longo dos anos no ensino público e gratuito. No projeto discentes dos cursos de Biologia, Biomedicina e Biotecnologia criaram vários outros materiais, sob a nossa supervisão (Cursos de extensão ministrados em 2010; Cursos de extensão ministrados em 2011; Jornal folha de botelhos, 2010). Alguns dos materiais didáticos comfeccionados no projeto também foram testados em escolas de Ensino Médio de Alfenas durante o trabalho de TCC. Alguns dos modelos desenvolvidos estão em fase de submissão e outros foram recentemente publicados, como é o caso do jogo denominado MUTA-AÇÃO (Gonçalves \& Gniech Karasawa, 2021).

Em função das observações feitas na Unifal, depois de assumir na UNESP, em 2019, demos continuidade no processo de validação do modelo sobre a estrutura da molécula de DNA. O intuito era verificar se utilizando grupos menores seríamos capazes de atingir um equilíbrio no processo de ensino-aprendizagem. No caso, o modelo foi testado na disciplina de genética com alunos de duas turmas de Agronomia, de Registro - São Paulo, com o objetivo de ajustar o tamanho do grupo de alunos para maximizar os resultados. Neste estudo realizado utilizamos apenas dois alunos por grupo e verificamos que nas aulas 
práticas houve participação de $100 \%$ dos alunos, todos mostraram um nível de compreensão elevado sobre o assunto, aumentou o foco e a concentração, o nível de colaboração e participação em sala de aula tornando o processo de ensinoaprendizagem mais dinâmico. Além disto, houve redução do uso de celulares tanto em aula prática quanto em aula teórica (Figura 5).

Figura 5. Detalhes da aula práticas de construção de modelos didáticos de baixo custo na disciplina de genética com alunos do curso de Agronomia da Unesp de Registro.

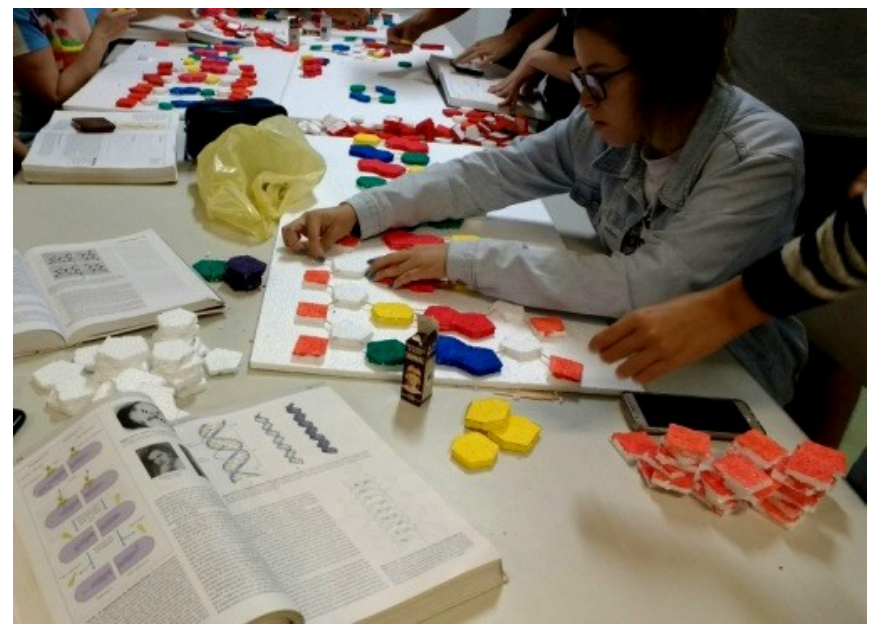

Observar que temos livros de genética e bioquímica dispostos sobre a mesa e os alunos interagindo estão focados na atividade da aula prática enquanto os celulares foram deixados de lado, fato bastante raro na atualidade. Fonte: Foto da autora.

A inserção da dobradura em papel na aula prática proposta por Yen (1995) aumenta eficiência e melhora ainda mais a compreensão da estrutura tridimensional da molécula de DNA, além de permitir que os alunos produzam uma molécula de DNA tridimensional (Figura 2), o que facilita a compreensão sobre a estrutura tridimensional do B-DNA (tais como: sulco maior, sulco menor, distância entre os pares de base em cada fita, etc) a um custo praticamente irrisório. Para maiores detalhes sobre a imagem do holograma para impressão sugerimos consultar o material publicado por Yen, (1995).

Em todos os casos citados supra-citados, verificamos nas diferentes disciplinas e cursos de graduação que houve aumento índice de aprendizado e memorização do tema abordado quando utilizado o modelo proposto, sendo o aluno capaz de detalhar com pormenores a estrutura da molécula de DNA (conhecimento verificado em prova e na montagem do modelo), exceto em grupos de 3-4 alunos. Além disto, produziu maior entrosamento na turma, exceto nas atividades individuais, colaboração e participação dos alunos em sala de aula, redução do índice de dispersão e uso de celulares, e produziu um ambiente mais descontraído nas aulas.

O uso de materiais didáticos tridimensionais manipuláveis para o ensino da estrutura da molécula de DNA se caracteriza por ser uma atividade inclusiva, pois permite que alunos com déficit de atenção, hiperatividade, com deficiências, entre outros, sejam beneficiados gerando maior compromentimento e aprendizado.

Outros autores já haviam constatado que o uso de modelos didáticos pode ser introduzido como ferramenta no processo ensino-aprendizagem para auxiliar o professor (Souza et al., 2020), pois eles facilitam o aprendizado do conteúdo em sala de aula aumentando a curiosidade dos alunos e qualidade do processo de ensino-aprendizagem (Santana \& Silva, 2010) e estimulam o trabalho em grupo entre os alunos permitindo a construção coletiva do conhecimento (Gerpe, 2020).

De acordo com Carvalho \& Oliveira (2021) os modelos didáticos são metodologias eficientes no ensino de citologia em atividades práticas e segundo Michelotti \& Loreto (2019) o uso de materiais didáticos tridimensionais também contribuem nas atividades inclusivas para deficientes visuais. Já, Fernandes e Locatelli (2021) utilizaram a técnica de produção de 
materiais didáticos para validar modelos com base no nível de compreensão e viabilizar a compreensão de temas de bioquímica utilizando representações na forma macro para ilustrar temas microscópicos e submicroscópicos tendo encontrado resultado satisfatório na melhoria da visualização dos temas testados. Entretanto, apesar da relevância dos materiais didáticos no processo de ensino-aprendizagem, o uso de modelos didáticos em sala de aula no ensino ainda é pouco explorado (da Silva et al., 2016).

\section{Considerações Finais}

Em relação aos quesitos avaliados verificou-se que trabalhos individuais de montagem da molécula, em geral, levaram a um maior foco e concentração, compreensão e aprendizado do tema, descrevendo minunciosamente a estrutura do DNA, além disso observou-se um capricho maior no trabalho entregue, entretanto os alunos se mostraram mais competitivos, com menor nivel de interação e colaboração e, maior grau de isolamento. Já, as atividades de 3 a 4 alunos por grupo, em geral, aumentaram a colaboração, reduzindo o isolamento, mas, em contrapartida, apresentaram individuos que não participaram da montagem e, consequentemente, estes mostraram grau menor de compreensão e menor índice de acertos nas atividades avaliativas, apresentaram, ainda, maior dispersão, menor foco e concentração. Por outro lado, atividades realizadas em grupos de 2 alunos mostrou-se ideal, pois os alunos apresentaram grande capacidade foco e concentração, elevado nível de acertos na montagem do modelo, boa capacidade para dissertar sobre a estrutura detalhando minúncias da molécula construída, ausência de isolamento, bom nível de colaboração e interação. Além disto, houve redução do uso de celulares e todos os alunos participaram da atividade.

A prática de metodologias alternativas no ensino, tais como o uso dos modelos didáticos tridimenisonais mostrou-se efetiva no processo de ensino-aprendizagem e possui grande relevância no ensino de temas de genética e biologia molecular em função do baixo custo quando comparado as aulas práticas tradicionais, da melhoraria na compreensão dos temas abordados, do aumento do envolvimento dos alunos e redução da dispersão durante as aulas, além de ter produzido uma aula mais descontraída. Além dos benefícios apontados, a redução crescente das verbas no ensino público torna o uso desta técnica bastante interessante e recomendada, pois o custo de adquisição de reagentes e equipamentos utilizados no ensino deste temas é bastante elevado chegando ao patamar da inviabilização de muitas práticas, além de não ser tão eficiente quanto o material didático aqui construído.Assim, o uso destas metodologias em salas de aula é recomendada para escolas com condições laboratoriais precárias, alunos com déficit de atenção, deficiência de visão, tímidos, entre outros, pois a manipulação de modelos tridimensionais de diferentes cores e texturas auxilia a compreensão e facilita o ensino de temas complexos, tais como a estrutura da molécula de DNA.

Com o avanço do conhecimento sobre a estrutura e a regulação da expressão gênica trabalhos futuros poderiam desenvolver um modelo incluindo os mecanismos epigenéticos que estão envolvidos no processo de expressão e silenciamento dos genes para viabilizar o aprofundamento no tema de biologia molecular.

\section{Agradecimentos}

Agradeço a Universidade Estadual do Sudoeste da Bahia (UESB), a Pró-Reitoria de Extensão da Unifal (PROEXT), a Universidade Federal de Alfenas (UNIFAL) e a Universidade Estadual Paulista “Júlio Mesquita Filho" (Unesp). Além disto, expresso minha gratidão aos revisores pelas valiosas sugestões e críticas muito oportunas que melhoraram a versão final do nosso trabalho.

\section{Referências}

Carvalho, C. L. L. de, \& Oliveira, D. B. de. (2021). O uso de modelos didáticos no ensino e aprendizagem de citologia. Brazilian Journal of Development, 7(2): 14765-14768. https://www.brazilianjournals.com/index.php/BRJD/article/view/24558/19624 
Cursos de Extensão ministrados em 2010: Desenvolvimento de materiais didáticos para professores. https://www.unifal-mg.edu.br/extensao/cursos-deextensao-ministrados-em-2010/

Cursos de Extensão ministrados em 2011: Popularização da genética - preparo de materiais didáticos . https://www.unifal-mg.edu.br/extensao/cursos-deextensao-ministrados-em-2011/

da Silva, A. A., da Silva Filha, R. T., \& Freitas, S. R. S. (2016). Utilização de modelo didático como metodologia complementar ao ensino da anatomia celular. Biota Amazônia, 6(3):17-21.

De Carneiro, J., \& Junqueira, L. C. U. (2012). Biologia Celular e Molecular. (9a ed.), Guanabarra Koogan, 376p.

Estrela, C. (2018). Metodologia cientifica: ciência, ensino e pesquisa. (3a ed.), Artes Medicas, 711p.

Fernandes, B. G., \& Locatelli, S. W. (2021). Acesso e Transição nos Níveis Representacionais durante a Construção de Modelos Explicativos acerca de Interações Intermoleculares. Revista Brasileira de Pesquisa em Educação em Ciências, e20017, 1-29. https://doi.org/10.28976/1984-2686rbpec2021u225253

Garcia, A. B., \& Macedo, J. M. B. (2009). Biologia molecular. (3a ed.), Fundação CECIERJ, 266p.

Gerpe, R. L. (2020). Modelos didáticos para o ensino de biologia e saúde: produzindo e dando acesso ao saber científico. Educação Pública, 20(15): 1-5. https://educacaopublica.cecierj.edu.br/artigos/20/15/modelos-didaticos-para-o-ensino-de-biologia-e-saude-produzindo-e-dando-acesso-ao-saber-cientifico

Gomes, A. A. (2008). Estudo de caso - planejamento e métodos. In.: Nuances: estudos sobre educação. Presidente Prudente, SP, ano XIV, 15(16): $215-221$.

Gonçalves, T. M., \& Gniech Karasawa, M. M. (2021). MUTA-AÇÃO: A proposta de um jogo lúdico sobre mutações e síndromes genéticas nas disciplinas de Biologia molecular e Genética Clássica. Arquivos do Mudi, 25(1): 44-65, 2021. https://periodicos.uem.br/ojs/index.php/ArqMudi/article/view/56371/751375151927

Gniech Karasawa, M. M., Vieria, B. F., Costa, C. A., Granato, E., Almeida, T. M. C. de, Maretti, T., \& Silva, E. A. (2010). Alunos recebem projeto popularização da genética. Jornal Folha de Botelhos, Edição 57, novembro.

Griffiths, A. J. F., Wessler, S. R., Carol, S. B., \& Doebey, J. (2016). Introdução à genética. (11a ed.), Guanabarra Koogan, 2036p.

Lüdke, M., \& André, M.D.E.A. (2018). Pesquisa em educação: abordagens qualitativas. (2a ed.), E.P.U., 112p.

Martins, L. A. P., \& Prestes, M. E. B. (2016). Mendel e depois de Mendel. Revista Genética na escola. 11(2), 244-249.

Michelotti, A. \& Loreto, E. L. da S. (2019). Utilização de modelos didáticos tateáveis como metodologia para o ensino de biologia celular em turmas $\begin{array}{llllllll}\text { inclusivas com } \quad \text { deficientes } & \text { visuais. } & \text { Revista } & \text { Contexto } & \text { \& } & \text { Educação, } & 34(109) \text { : }\end{array}$ https://www.revistas.unijui.edu.br/index.php/contextoeducacao/article/view/8686

Nelson, D. L., \& Cox, M. M. (2014). Lehninger: Princípios de bioquímica. (6a ed.), Artmed, 1220p.

Pereira, A. S., Shitsuka, D. M., Pereira, F. J., \& Shitsuka, R. (2018). Metodologia da pesquisa científica. Santa Maria, RS:UFSM, NTE, 119p.

Pierce, B. (2017). Genética: um enfoque conceitual. (5a ed.), Guanabarra Koogan, 1206p.

Ramalho, M. A. P., Santos, J. B. dos, \& Pinto, C. A. B. P. (2012). Genética na Agropecuária. UFLA, 472p.

Santana, A. S. \& Da Silva, I. A. (2010). A importância de modelos didáticos no ensino aprendizagem de neurociências. Saúde \& Ambiente em Revista, 5(2). http://publicacoes.unigranrio.edu.br/index.php/sare/article/view/1148

Santos, F. D. dos, Silva, A.F.G. \& Franco, F. F. (2015). 110 anos após a teoria Soutton-Boveri: a teoria cromossômica da herança é compreendida pelos Brasileiros? Ciência e Educação, 21(4):2015. https://www.scielo.br/j/ciedu/a/Tkndcjnt7sS9XqXp7G6mSxf/?lang=pt

Silva, M. L. M., Silva, M. G. L. da. (2018). DNA: diálogo, genética e argumentação. IFRN, 135p.

Silva, L. A. G. da, Snustad, D. P., Simm\& Mercês, N. N. da. (2017). Estudos de casos múltiplos aplicado na pesquisa de enfermagem: relato de experiência. Revista Brasileira de Enfermagem, 71(3): 1194-1197.

ONS, M. J. (2013). Fundamentos de genética. (6a ed.), Guanabarra Koogan, 2013. 762p.

Souza, K. M. S. de, Souza, K. T. V. de, Cavalcanti, M. T. H. \& Porto, A. L. F. (2020). Elaboração de modelos moleculares para o ensino de bioquímica. Cadernos de Educação Básica, 5(2): 1-17. http://www.cp2.g12.br/ojs/index.php/cadernos/article/view/2772/1767

Yen T. (1995). Make your own DNA (Origami's answer to oligonucleotide synthesis). Trends Biochem Sci., 20(2):94. 10.1016/s0968-0004(00)88970-7. PMID: 7701571.

Zaha, A., Ferreira, H. B., \& Passaglia, L. M. P. (2014). Biologia molecular básica. (5a ed.), Artmed, 403p. 